\title{
Erratum to: The Minimum Clinically Important Difference of the Patient-rated Wrist Evaluation Score for Patients With Distal Radius Fractures
}

Monique M. J. Walenkamp MD, MSCE, Lara M. Vos MD, Robert-Jan de Muinck Keizer MD, Melvin P. Rosenwasser MD, J. Carel Goslings MD, PhD, Niels W. L. Schep MD, PhD, MSCE

Published online: 9 July 2015

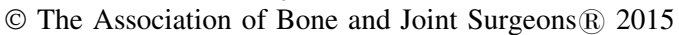

\section{Erratum to: Clin Orthop Relat Res \\ DOI 10.1007/s11999-015-4376-9}

In the published study, the order of the authors is incorrect. The correct order of the authors is given in this erratum.

The authors apologize for the error.

The online version of the original article can be found under doi:10.1007/s11999-015-4376-9.

M. M. J. Walenkamp (凹), L. M. Vos, R.-J. de Muinck Keizer,

J. C. Goslings, N. W. L. Schep

Academic Medical Centre, University of Amsterdam,

Meibergdreef 9, 1105 AZ Amsterdam, The Netherlands

e-mail:m.m.walenkamp@amc.nl

M. P. Rosenwasser

Department of Orthopedic Surgery, Columbia University

Medical, New York, NY, USA 